\title{
A interdisciplinaridade em prática: ou como um conceito abstrato toma forma em teses de doutorado do PPGICH.
}

Os textos a seguir, que formam o Dossiê Interdisciplinaridade desse número dos Cadernos de Pesquisa Interdisciplinar em Ciências Humanas, foram resultado de um desafio apresentado numa das sessões da disciplina de Epistemologia e Metodologia de Pesquisa, no PPGICH. Essa disciplina proporcionou um diálogo muito produtivo entre diversos professores do programa e os alunos da turma 2007, que mais do que aulas ofereciam em cada encontro os segredos de como realizavam suas pesquisas, contanto algo como o making off das suas próprias teses, livros e artigos. A todos foi perguntado também sobre como viam a interdisciplinaridade no seu trabalho. Infelizmente, porém, não fizemos o registro de suas respostas - o que ficará, talvez, para um dossiê futuro, sugestão que já deixamos ao editor.

O desafio que resultou neste dossiê foi o de tentar capturar também nos trabalhos finais dos doutorandos como a interdisciplinaridade vem sendo desenvolvida no PPGICH. Com uma capacidade de organização originada talvez de sua formação disciplinar anterior, Naira Tomiello, uma das alunas da turma, tomou para si a tarefa de sistematizar as discussões sobre a elaboração desse trabalho e enquadrá-las em um roteiro que fosse mais ou menos consensual. A turma de doutorandos então, dividida nas suas respectivas áreas de concentração de Estudos de Gênero (Paula e Felipe), de Sociedade e Meio Ambiente (Naira, Ivana, Mariuze e Jerônimo) e de Condição Humana na Modernidade (Rosa e Paulo), se debruçou avidamente sobre o trabalho. O trabalho consistia na leitura das teses de doutorado defendidas nas suas áreas e na sua análise, ressaltando-se os trechos que refletiam uma interdisciplinaridade. Como se pode ler nos artigos que resultaram dessa análise, há diferenças significativas no modo como em cada área se pratica a interdisciplinaridade.

O trabalho foi completado com o depoimento direto dos egressos que responderam a um questionário elaborado por Naira. Agradecemos as respostas de Adriano Henrique Nuernberg, Álvaro Afonso Simon, Amanda Péres Montañés, Ana Lúcia Santos Verdasca Guimarães, Ângela Maria de Moraes Bertho, Ariane Kuhnen, Brena Paula Magno Fernandez, Carlos Alberto de Souza, Cristiana Tavares da 
Costa Rocha, Cristiana Tramonte, Cristiane Mansur de Moraes Souza, Fernando Oliveira Noal, Gilberto Montibeller-Filho, Leandro Castro Oltramari, Luiz Fernando Neves Córdova, Sandra Makowiecky e Tito Sena.

O dossiê que Cadernos de Pesquisa publica nesse número serve assim como um primeiro balanço desses 15 anos desse espaço interdisciplinar, um dos poucos no país institucionalizado como tal, que é o PPGICH.

Boa leitura.

Carmen Rial Naira Tomiello 